\title{
The Role of Inflexible Friendship Beliefs, Rumination, and Low Self-worth in Early Adolescents' Friendship Jealousy and Adjustment
}

\author{
Kristen L. Lavallee • Jeffrey G. Parker
}

Published online: 1 April 2009

(C) Springer Science + Business Media, LLC 2009

\begin{abstract}
Two focal social cognitive processes were evaluated in a structural model for their direct and indirect roles in early adolescents' jealousy surrounding their closest friend in a sample of 325 early adolescents (169 girls and 156 boys) ages 11-14 years. Individuals who are rigid and unrealistic about meeting their friendship needs were more vulnerable to feelings of jealousy than individuals who think more flexibly. Inflexible individuals also engage in more jealousy-driven surveillance and other problem behavior towards their friends. Stronger jealous feelings and behavior were related, in turn, to greater conflict with friends and to a vulnerability to emotional maladjustment. In addition, young adolescents who tended to ruminate over friendship problems were also more vulnerable to jealousy. Inflexible attitudes and friendship rumination were positively associated. Results extend
\end{abstract}

This study was completed in partial fulfillment of the requirements for a master's degree awarded to the first author by The Pennsylvania State University, University Park, PA, and was supported in part by National Science Foundation grant BCS0451261, awarded to the second author. Portions of this study were presented at the biennial meetings of the Society for Research in Child Development, Tampa, FL, April 2003. We deeply appreciate the students and staff of Tyrone Area School District for their assistance and participation in the project, as well as the research assistants and graduate students of the Friendship Project at The Pennsylvania State University for their assistance in data collection.

K. L. Lavallee $(\bowtie)$

Institut für Psychologie, Universität Basel,

Missionstrasse 62,

CH-4055 Basel, Switzerland

e-mail: Kristen.Lavallee@unibas.ch

J. G. Parker

Institute for Social Science Research, University of Alabama,

Tuscaloosa, AL 35487-0216, USA

e-mail: J.G.Parker@ua.edu recent models of friendship jealousy that focus only on early adolescents' self-worth.

Keywords Friendship · Jealousy · Loneliness · Depression . Inflexibility - Social cognition · Preadolescent - Adolescent . Rumination · Self-worth · Self-esteem · Flexible thinking . Friendship conflict

Recently, Parker and colleagues (Parker et al. 2005; Parker and Ramich 2003; Roth and Parker 2001) provided a framework for conceptualizing and assessing children's vulnerability to jealousy surrounding friends. Drawing upon research with adults in romantic contexts (e.g., Buunk 1997; Clanton 1981; Guerrero and Anderson 1998; Parrott and Smith 1993; Pfeiffer and Wong 1989; Salovey and Rodin 1989; White 1981), Parker et al. conceptualized friendship jealousy in childhood as a negative cognitive, emotional, and behavioral reaction triggered by a close friend's actual or anticipated interest in or relationship with another peer. According to these authors, jealousy is based upon the target's perception that the partner's relationship with someone else puts the target's relationship in jeopardy. However, even when their relationship with their partner continues, jealous individuals may anticipate a diminution of the quality or exclusivity of the relationship. As a result, these children will be at risk for engaging in behaviors that alienate peers and jeopardize their chances of maintaining supportive and satisfying close friendships.

To support this view, Parker et al. reported findings on friendship jealousy with several samples of early adolescents from 10 to 14 years (Parker and Gamm 2003; Parker et al. 2005; Roth and Parker 2001), confirming individual differences in the degree to which children react negatively to their friend's outside social activities. These individual differences were highly consistent across diverse situations 
and stable over time, with girls and younger children reporting higher levels of jealousy than boys and older children. Further, friendship jealousy was associated with greater loneliness and dissatisfaction with peer experiences in general. Moreover, children with reputations for friendship jealousy also behaved in aggressive ways, were less well-liked by peers in general, had more mutual peer enemies, and were victimized by peers.

Parker et al.'s (2005) findings provide a beginning basis for a much-needed understanding of the role of the social context in friendship. Yet, they also raise important questions around the cognitive, motivational, or other factors at the root of this vulnerability. Parker et al. posited that individuals with low self-worth may be prone to jealousy because they are prone compare themselves unfavorably to friends' friends, fueling their insecurity by exaggerating the risk that outsiders pose to their friends' commitment to the relationship (e.g., Mathes 1991; Sharpsteen 1991; White 1981). However, Parker et al. obtained only a modest positive correlation between jealousy and self-esteem, suggesting that other factors may be at work.

The present research broadens understanding of the psychological vulnerability of early adolescent friendship jealousy by extending the focus to include consideration of young adolescents' views of others and processing of information about relationships. In particular, along with perceptions of self-worth, we consider individual differences in two connected, key social-cognitive processes. Although social-cognitive models have frequently been used to understand adults' emotional and behavioral responses to relationship events (e.g., Baldwin 1992; Bradbury and Fincham 1991; Fletcher and Fitness 1990) or children's behavior in general (e.g., Crick and Dodge 1994; Lemerise and Arsenio 2000), fewer studies have examined variations in children's friendship experiences from this perspective (for an exception, see Erdley and Asher 1999).

The first process concerns the rigidity versus flexibility of early adolescents' beliefs concerning the interpersonal functions of specific friends. Flexibility is an inherent requirement of relationship participation at all ages (Selman and Schultz 1990). Unique social opportunities pass, anticipated events are cancelled, and preferred partners are unavailable or behave unpredictably. Such circumstances need not provide more than temporary disappointment and frustration if relationship participants recognize and accept their inevitability. Individuals must be prepared to reevaluate specific social goals; devise alternate means to specific ends, or accept interim outcomes without undue bitterness.

Flexibility has been indirectly implicated in adaptive functioning in a number of broad models of cognition in close relationships. For example, models of interpersonal cognition stress how expectancies, values, attributions, and related judgment heuristics affect perceptions and behavior within relationships (e.g., Crick and Dodge 1994; Lemerise and Arsenio 2000). Within these frameworks, flexible recognition of contextual cues for behavior is regarded as a hallmark of social competence (see also Selman and Schultz 1990). Flexibility has also surfaced in efforts to understand the role of goals, needs, and other motivational orientations in individuals' responses to interpersonal disappointments. Work in this broad tradition generally assumes that responses to relationship events are governed by relational and personal goals, how rigidly and narrowly those goals are defined, and whether individuals cling to goals that have become counterproductive. For example, Martin and colleagues (e.g, Martin and Tesser 1996; McIntosh et al. 1995; McIntosh and Martin 1992; McIntosh et al. 1997) suggest everyday relationship disappointments can lead to distress when vulnerable individuals rigidly link concrete events and attainments (e.g., attending a specific social activity) to personal happiness. Disappointments connected to these specific goals are relatively major events for individuals who think in this rigid way.

Although typically used to describe adults, these models can generate hypotheses concerning early adolescents' responses to relationship events. Specifically, we hypothesize that young adolescents who are insistent that only specific other individuals can fulfill the interpersonal functions of friendships will be vulnerable to feeling threatened by perceived interference in their relationships. Such individuals are inflexible in that they unrealistically regard their preferred means (i.e., their best friend) to an interpersonal end (e.g., having someone to confide in) as the only means, and ignore alternative options (e.g., less close friends) that others find viable in the same circumstances. Thus, when outsiders inevitably encroach on their friendship activities, they perceive greater threat, and their experience and expression of jealousy is commensurately stronger.

The second process of interest is the tendency of some adolescents to ruminate over perceived problems with friends. Ruminative thought is repetitive, unwanted, and unnecessary unproductive thought surrounding a common theme (e.g., Martin and Tesser 1996). Although positive forms of ruminative thought have been recognized (e.g., reminiscing, positive anticipation of the future, see Martin and Tesser 1996), rumination that involves regret, feelings of failure, worry, or concerns about competence, is associated with a number of adjustment difficulties in adults, including unhappiness (McIntosh and Martin 1992), depression (e.g., Nolen-Hoeksema et al. 1993; Pyszczynski and Greenberg 1987), anxiety (e.g., Nolen-Hoeksema 2000), and problematic social and cognitive problemsolving (e.g., Carver et al. 1989; Davis and Nolen- 
Hoeksema 2000). Of particular interest, in adults, rumination over romantic relationships is related to greater possessiveness of partners and to counterproductive coping strategies such as surveillance, distancing, and destructive communication (Carson and Cupach 2000).

Although scant, existing work on ruminative thought in children supports both the feasibility of measuring individual differences in rumination at younger ages (e.g., Broderick 1998) as well as its significance for adolescents' adjustment, including its links to depression (Hart and Thompson 1996; Rose 2002; Schwartz and Koenig 1996). In the present study, we anticipated that individuals with inflexible attitudes would be more likely to see friendship disappointments as more central to their well being and ruminate over them. Because one important broad class of friendship disappointment follows from outside interference in these relationships, we further anticipate that rumination will provide some of the impetus to feelings of jealousy.

Figure 1 includes a summary of the hypothesized relations among self-worth, inflexible thought, rumination, and vulnerability to experiencing feelings of friendship jealousy. As the left portion of this figure shows, the roots of the disposition to friendship jealousy rest partly in early adolescents' negative views of themselves, consistent with previous research. However, in a departure from prior work, in the current study, jealousy is also proposed to stem from inflexible attitudes regarding which specific other individuals can fulfill their friendship needs. Negative views of the self and friendship inflexibility are likely positively related (i.e., the tendency to feel negative and insecure about oneself is related to poorer utilization and organization of social information, see Miller 1996); therefore a reciprocal relation between these variables is also posited. Moreover, low self-worth and inflexible thinking are expected to have secondary consequences that further jealousy. In particular, because inflexible early adolescents link their interpersonal needs so closely to a specific friend, disappointments with friends are likely to loom larger for them than for others and they are anticipated to ruminate surrounding the status of their friendships and the intentions of their friends (McIntosh and Martin 1992), further exacerbating jealousy (see Fig. 1).

Consideration of inflexible beliefs and rumination also affords an opportunity to extend current understanding of the inter- and intrapersonal consequences of friendship jealousy. These additional hypotheses are also represented in Fig. 1. No necessary relation exists between experiencing jealousy and expressing it, but jealous individuals are normally strongly motivated to act to preserve the relationship or restore self-esteem (Buunk and Bringle 1987; Guerrero and Afifi 1999; Guerrero et al. 1995). Although positive behavioral responses exist, problematic, and even violent, responses are common in adults. Indeed, jealousy is a major contributor to relationship dissatisfaction and dissolution among adults (Anderson et al. 1995; Bringle et al. 1979; Hansen 1991; Stets and Pirog-Good 1987).

Early adolescents' behavioral responses to friendship jealousy are comparatively poorly understood. As noted, existing work indicates that vulnerable children are also aggressive in the peer group at large (Parker et al. 2005). Whether and how jealousy also compromises vulnerable individuals' friendships is almost completely unknown at present, however, and no framework for understanding adolescents' jealous responses has been described to date. For the present study, we drew upon several tenets of uncertainty reduction theory within social psychology (e.g, Berger and Gudykunst 1991; Berger and Kellermann 1994; Guerrero et al. 1995; Planlap and Honeycutt 1985) to predict a select category of maladaptive jealousy responses likely to undercut these early adolescents' friendships by

Fig. 1 Conceptual model of the roles of self-worth, inflexibility, and rumination in jealousy, friendship difficulties, and emotional maladjustment

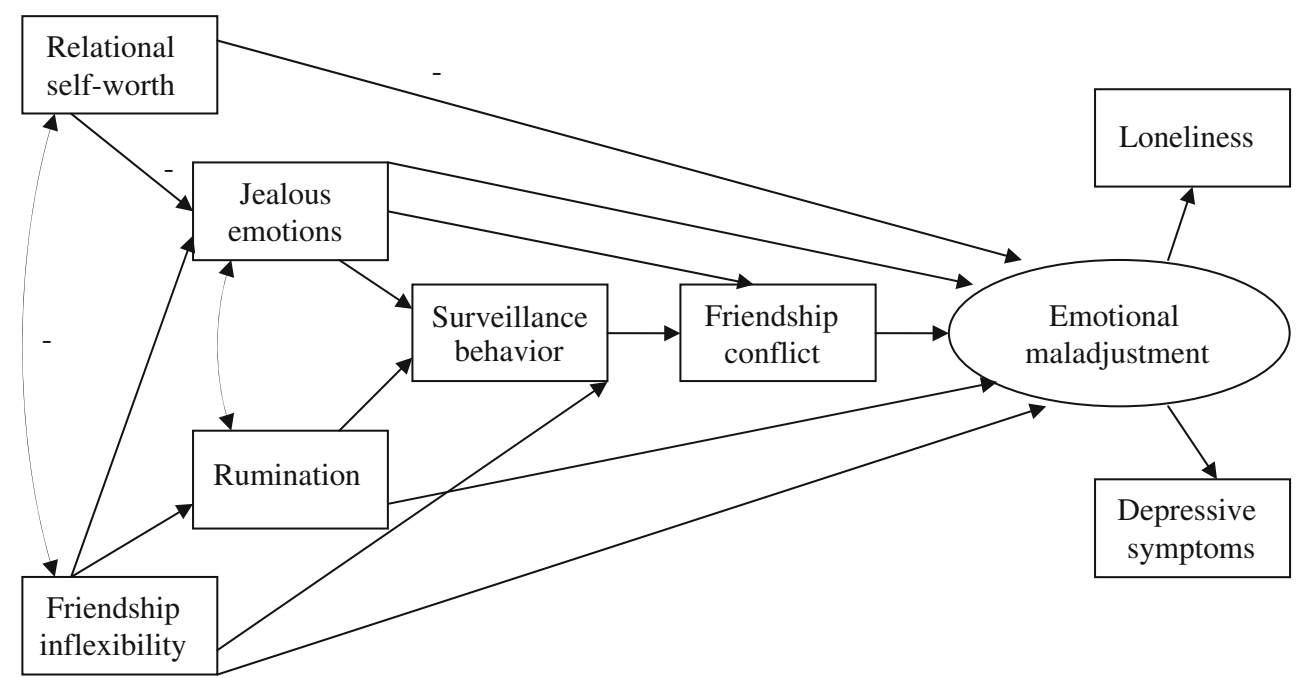


contributing to conflict. According to uncertainty reduction theory, ambiguity surrounding relationships is unpleasant and individuals are highly motivated to reduce it through information gathering. Direct communicative strategies (e.g., asking partners directly about their intentions and commitment) exist, but face-saving goals often inspire indirect strategies, such as making inquiries to thirdparties, surreptitious observation of partners in revealing settings, and creating contrived events or settings that may diagnose a partner's motives and loyalties (Carson and Cupach 2000; Pfeiffer and Wong 1989).

In the present context, we hypothesized that inflexible friendship beliefs and a proneness to ruminate over friendship problems also inspire young adolescents to engage in covert monitoring and other surveillance activities designed to clarify their partners' and rivals' intentions (see Fig. 1). However well they meet the short-term information-gathering goals of jealous individuals, such responses may have the unintended consequence of contributing to interpersonal conflict with friends (see Fig. 1). Prior research suggests that, when habitual, relationship partners find such behaviors to be burdensome, demeaning, and a violation of norms of autonomy in friendship (Rawlins 1992; Selman 1980).

Finally, as both rumination and inflexible thought have both been implicated in vulnerability to depressive symptoms in past research (e.g., McIntosh and Martin 1992; Rose 2002), in the present study we predict that low selfworth, inflexible friendship beliefs, rumination over friendship problems and feelings of jealousy will each directly contribute to emotional maladjustment as indexed by a combination of loneliness (following Parker et al. 2005) and reports of depressive symptoms. Moreover, inflexible beliefs, rumination, and jealousy are also expected to contribute indirectly to emotional maladjustment by contributing to surveillance behavior and thereby interpersonal conflict with friends (see Fig. 1).

In sum, the present study was designed to extend promising early work on friendship jealousy by evaluating an expanded model of its antecedents and consequences. The model elaborates the presumed consequences of jealousy by exploring links among jealousy, uncertainty-reducing surveillance and related negative friendship behaviors, friendship conflict, and emotional maladjustment. However, the model's most notable feature is its emphasis on the social cognitive processes of inflexible beliefs and rumination. It is argued that early adolescents' vulnerability to jealousy is increased when they think inflexibly about how specific individuals meet broader friendship objectives. Inflexible thinking provides a pathway to jealousy outside the focus in the past on self-worth and, among other things, is anticipated to contribute to the tendency to ruminate over friendship difficulties. Rumination, in turn, is another expected contributor to jealousy. Together, inflexible thinking and rumination are also expected to exacerbate negative friendship behavior, friendship conflict, and emotional maladjustment.

To test these hypotheses, we employ structural equation modeling with a sample of early adolescents and a newly created self-report measure of friendship inflexibility. Preliminary data on the test-retest stability of this measure are also presented, along with beginning evidence for its discriminant validity. In addition, as past research suggests that, compared with boys, girls report greater jealousy (Parker et al. 2005), depression (Hart and Thompson 1996), and rumination (Broderick 1998; Nolen-Hoeksema et al. 1999; Rose 2002; Schwartz and Koenig 1996), we anticipate that girls will be higher than boys in these areas. However, sex differences in the hypothesized pathways among variables are not anticipated, as there is little historical basis for such an expectation.

\section{Method}

Participants and Procedure

The present study was approved by the institutional review board at The Pennsylvania State University. Participants were 325 early adolescents, attending a single, rural middle school, including 66 girls and 59 boys in sixth grade, 48 girls and 45 boys in seventh grade, and 55 girls and 52 boys in eighth grade. The sample was representative of the community from which it was drawn, which, according to census records, was primarily Caucasian (approximately 98\%) and of low to middle-class socioeconomic status (per capita income was $\$ 15,285$; Census 2000). A random subgroup of 61 children (11 girls, nine boys in sixth grade, eight girls, four boys in seventh grade, 15 girls, 14 boys in eighth grade) also participated in a 2-month retest evaluation of the inflexibility measure.

Families of potential participants were sent letters detailing the study and soliciting parental consent, and research staff visited classrooms to describe the study to children. All participants received a token gift in appreciation for their participation. However, as an incentive for returning consent forms (regardless of the decision to participate), students were promised that drawings for a \$20 gift certificate would be held for all members of every homeroom class with greater than a $90 \%$ return rate. Three individual homerooms reached this threshold and earned drawings. Across all classrooms, approximately $87 \%$ of eligible sixth graders, $62 \%$ of eligible seventh graders, and $55 \%$ of eligible eighth graders obtained parental consent to participate. There was no minimum classroom participation 
rate, and all students with written parental consent and adolescent assent were included in the study.

Participants completed a booklet of the questionnaires during group testing in their classrooms on two occasions approximately three weeks apart. In these sessions, a trained research assistant read instructions aloud to students. Individual questions were read aloud to students with reading difficulty. Across classrooms, the order of measures within booklets was random. Both sessions were less than $50 \mathrm{~min}$ in length.

\section{Measures}

Friendship Inflexibility. Participants' inflexibility surrounding friends was assessed using a 16-item questionnaire. Individuals high on this newly-developed measure express an unwillingness to accept a reasonable short-term substitute activity or individual when frustrated by a friend, and the unworkable belief that their current best friend is the only conceivable individual who can fulfill their needs for companionship, intimacy, support, and fulfillment. Items included both abstract and more concrete manifestations of inflexibility, such as: "There is only one person I could see myself being best friends with," and "If I had a birthday party, but my best friend couldn't come, I would still have fun with the other kids there" (reversed). For each item, respondents indicate the degree to which each statement accurately describes them using a Likert scale ranging from 1 ("not at all true") to 5 ("really true"). Scores are obtained by averaging across items (after reverse scoring as appropriate).

The inflexiblity measure was developed through extensive pilot testing, including the use of principal components factor analysis to reduce an original pool of 18 items to the 16 items. Loadings from this analysis supported the interpretation of single latent factor. In addition, supplemental testing indicated that friendship inflexibility scores were moderately positively correlated with a inflexible perseveration during abstract cognitive reasoning tasks (e.g., the Wisconsin Card Sorting Test) and independent of general cognitive ability and the influence of social desirablility, providing preliminary convergent and discriminant validity for this task. ${ }^{1}$ Internal consistency for the final scale was 0.87 .

Feelings of Friendship Jealousy Participants' characteristic and current feelings of jealousy surrounding their closest friend were assessed by combining items from two existing assessments. An initial set of items consisted of items from the Friendship Jealousy Questionnaire developed by Parker et al. (2005). Due to time constraints, only ten of the 15

\footnotetext{
$\overline{{ }^{1} \text { Unpublished }}$ data available upon request from authors,
}

primary items were used. In these items, respondents are presented with short vignettes depicting hypothetical social situations featuring themselves, their self-identified closest best friend, and a hypothetical third party peer. The best friend and third party in these vignettes appear to be getting along well or engaging in social activities without the participant (e.g., "You call your best friend to see what's up and if she has made plans for the evening and she says that she can't talk right now because another girl that you both know is over"). Participants are asked to indicate how jealous they would feel under such circumstances using a scale of 0 (not at all true of me) to 4 (very true of me).

In addition, participants completed six items adapted from items developed by Pfeiffer and Wong (1989) for use with adults. These items focused more specifically on the participant's current jealous worries and concerns surrounding the participant's self-identified best friendship (e.g., "I am worried that my best friend is becoming better friends with someone else"). Participants rated these items on a scale of 1 (never) to 7 (always). Factor analysis supported standardizing all 16 items and compositing them into a single scale. The factor loadings for the items of this scale ranged from 0.59 to 0.76 and internal consistency was $\alpha=0.93$.

Surveillance Behavior Eight further items from Pfeiffer and Wong (1989) were used to assess the extent to which participants admitted engaging in surveillance and related uncertainty-reducing negative jealous behaviors surrounding their best friend (e.g., "I call my friend unexpectedly, just to see if he or she is there"). As before, respondents rated items on a scale of 1 (never) to 7 (always). Internal consistency for this assessment was also adequate, $\alpha=0.80$.

Friendship Conflict and Closeness Assessments of friendship conflict and closeness were obtained using items taken from the Friendship Quality Questionnaire (Parker and Asher 1993). Parker and Asher's (1993) original scale consists of 41 items designed to assess the quality of a child's perceived best friendship along six dimensions: Conflict, and five dimensions of closeness (companionship and recreation, personal validation and caring, help and guidance, intimate disclosure, and conflict resolution). Respondents were asked to think of their best friend and indicate whether each item is accurate for this friendship using a continuous scale from 0 (not at all true) to 4 (really true). Sample items include "We get mad at each other a lot," and "We make each other feel important and special." In the present study, the original three-item conflict scale was retained. This scale displayed adequate internal consistency, $\alpha=0.78$. Due to time constraints, however, only 14 of the 38 original closeness items were retained by selecting six items from the validation and help domains and eight items from the companionship and intimacy 
domains. These 14 items were averaged to yield a single scale of friendship closeness, with $\alpha=0.87$.

Depressive Symptoms Depressive symptoms were assessed using seven items from the Children's Depression Inventory-Short Form (Kovacs 1992). Items referring to feelings of loneliness, having friends, physical appearance, and suicide ideation were dropped because they were redundant with other questionnaires or irrelevant to the focus of the current study. Participants were asked to select the best fitting of three alternative statements for each item (e.g., "I am sad once in a while, I am sad many times, I am sad all the time"). Responses are rated from 0 to 2, with high scores indicating a high level of depression. Internal consistency was adequate across the seven items, $\alpha=0.85$, and a single score was calculated from the mean of all items.

Loneliness and Social Dissatisfaction Following Parker and Asher (1993), participants' loneliness surrounding peers was assessed using three items taken from the 16item Illinois Loneliness scale (Asher and Wheeler 1985). These items tapped children's feelings of being alone at school (e.g., "I feel alone at school," "I feel left out of things at school," and "I'm lonely at school"). Children rated each item on a scale from 1 ("not at all true") to 5 ("really true). Parker and Asher (1993) report that this short version of the measure is strongly correlated with the longer, original measure $(r=0.84, p<0.05)$. Internal consistency was $\alpha=.89$ in the present study, and a single score was calculated from the mean of all items.

Relational Self-Worth The six-item Global Self-Worth scale from the Self-Perception Profile for Adolescents (Harter 1988) assessed participants" satisfaction with themselves in the context of their peers and friends (Harter et al. 1998). Students read one negatively- and one positively-valanced statement for each item (e.g., "Some students are often unhappy with themselves when they are around their friends," and "Other students are pretty pleased with themselves when they are around their friends.") and selected the one most like them. Respondents then indicated whether the item is "sort of true" or "really true" of them. Scores range from 1 ("sort of true of me" on first statement) to 4 ("really true of me" on second statement). This measure demonstrated high internal consistency, $\alpha=0.81$.

Friendship Rumination A 7-item rumination scale, based on measures by Rose (2002) and Nolen-Hoeksema and Morrow (1991), was developed to assess participants' ruminative coping in response to problems with friends. For each item, respondents were presented with examples of ruminative thought and asked to indicate the extent to which it was typical of their behavior when they encountered a problem with a friend (i.e., "I think about every part of the problem over and over"). Ratings were made on a Likert scale ranging from 1 (almost never) to 4 (almost always). Internal consistency for this scale was high, $\alpha=0.89$.

\section{Results}

\section{Preliminary Analyses}

Friendship Inflexibility Validation Consistent with expectations, assessments of participants' friendship inflexibility were relatively stable over the re-test period, $r=0.63, p<$ 0.001 . In addition, as expected, inflexibility was unrelated to the closeness of the best friendship relationship as reported by the participant, $r=0.06$, ns.

Sex and Grade Differences in Primary Variables A 2 (sex) X 3 (grade) Multivariate Analysis of Variance (MANOVA) was performed on the eight primary variables to be included in subsequent structural modeling. Results revealed a statistically significant multivariate main effect of sex, $F(8,293)=$ 6.63, $p<0.01$. Neither the test for grade, $F(16,588)=1.20$, nor the sex $\mathrm{X}$ grade interaction, $F(28,388)=1.34$, were statistically significant. Follow-up univariate analyses revealed sex differences in friendship inflexibility, $F(1$, $319)=14.20, p<0.01, d=0.42$, jealous feelings, $F(1,322)=$ 23.63, $p<0.05, d=0.54$, surveillance behavior, $F(1,319)=$ $11.05, p<0.01, d=0.54$, loneliness, $F(1,319)=7.28$, $p<0.01, d=0.30$, and friendship rumination, $F(1,318)=$ $21.89, p<0.01, d=0.52$. Relative to boys, girls reported higher inflexibility $\left(M_{\text {boys }}=2.33, \mathrm{SD}=0.75\right.$ versus $M_{\text {girls }}=$ $2.65, S D=0.79)$, feelings of jealousy $\left(M_{\mathrm{boys}}=0.20, S D=0.68\right.$ versus $M=0.17, S D=0.68)$, surveillance behavior $\left(M_{\mathrm{boys}}=\right.$ 2.21, $S D=1.02$ versus $M_{\text {girls }}=2.58, S D=1.01$ ), loneliness $\left(M_{\text {boys }}=1.52, S D=0.79\right.$ versus $\left.M_{\text {girls }}=1.80, S D=1.05\right)$, and rumination $\left(M_{\mathrm{boys}}=2.59, S D=1.01\right.$ versus $M_{\text {girls }}=3.10, S D=$ $0.95)$. There were no sex differences in self-worth $\left(M_{\text {boys }}=\right.$ 3.31, $\mathrm{SD}=0.61$ versus $M_{\text {girls }}=3.30, S D=0.67$ ), depression $\left(M_{\mathrm{boys}}=1.28, \mathrm{SD}=0.40\right.$ versus $\left.M_{\text {girls }}=1.36, S D=0.45\right)$, or friendship conflict $\left(M_{\mathrm{boys}}=2.18, \mathrm{SD}=0.96\right.$ versus $M_{\text {girls }}=$ 2.00, $S D=0.92$ ).

Pathways to Jealousy and Emotional Adjustment: Structural Model

Table 1 presents the bivariate correlations among the eight primary variables included in structural equation evaluation of the hypothesized path model outlined in Fig. 1. 
Coefficients for girls and boys appear below and above the diagonal respectively. As we were not only interested in the significance of individual pathways, but also the potential incremental improvement in fit accompanying the incorporation of the key social cognitive processes of inflexible thinking and rumination, we tested the model in Fig. 1 in two nested stages for descriptive clarity. First a reference model was established that included all pathways in Fig. 1 except pathways to or from inflexible thinking and rumination. With this benchmark established, the complete model that incorporated the remaining information concerning inflexibility and rumination was then fit, its parameters evaluated, and its comparison to the baseline model noted.

Model testing was conducting using the 306 participants (159 girls, 147 boys) with complete data on the relevant measures using the maximum likelihood procedure in AMOS (Arbuckle and Wothke 1999). No a priori conceptual basis existed for anticipating changes in model paths with grade. Also, preliminary analyses did not reveal grade differences for the model variables. Thus, to simplify evaluation, grade was not explicitly considered in model testing (i.e., the model was tested by pooling across grades). However, the regression and covariance coefficients of the full model were tested for equivalence across sex using a parsimony-driven multi-group approach. Specifically, the full model was fit initially assuming invariance in the paths and covariances across the sexes. After the fit of this model was assessed, each of its included pathways was individually evaluated for invariance across sex by examining the critical ratio associated with the pathway when the pathway was freely estimated for the two sexes. The model was then re-specified a final time after including freely estimated coefficients for any pathways in which critical ratios exceeded conventional significance $(p<0.05)$. The fit of the less restrictive final model was then compared to the fully-restricted model and retained only if it appeared warranted by a statistically significant improvement in fit.

Figure 2 depicts the standardized path and covariance estimates from the reference model, in which links among early adolescents' self-evaluation, jealousy, friendship conflict, and emotional maladjustment were modeled without the benefit of information regarding the individuals' flexibility and rumination. Pathways depicted with solid lines were statistically significant at $p=0.05$ or greater. Predicted pathways that were not significant are depicted with dashes. For clarity, error estimates for measured and latent variables are not displayed. Results indicated that this interim model provided an inadequate overall fit. The chi square was statistically significant, $\chi^{2}(54)=190.47, p<$ 0.001 , and the relative fit indices (TLI $=0.74, \mathrm{CFI}=0.75$; Bentler and Bonett 1980; Hu and Bentler 1995) indicated inadequate fit compared to an appropriate independence 
Fig. 2 Baseline structural model considering only the role of self-worth in jealousy and adjustment. Note. All coefficients are standardized. All coefficients except those with a dashed line are statistically significant at $p<0.05$

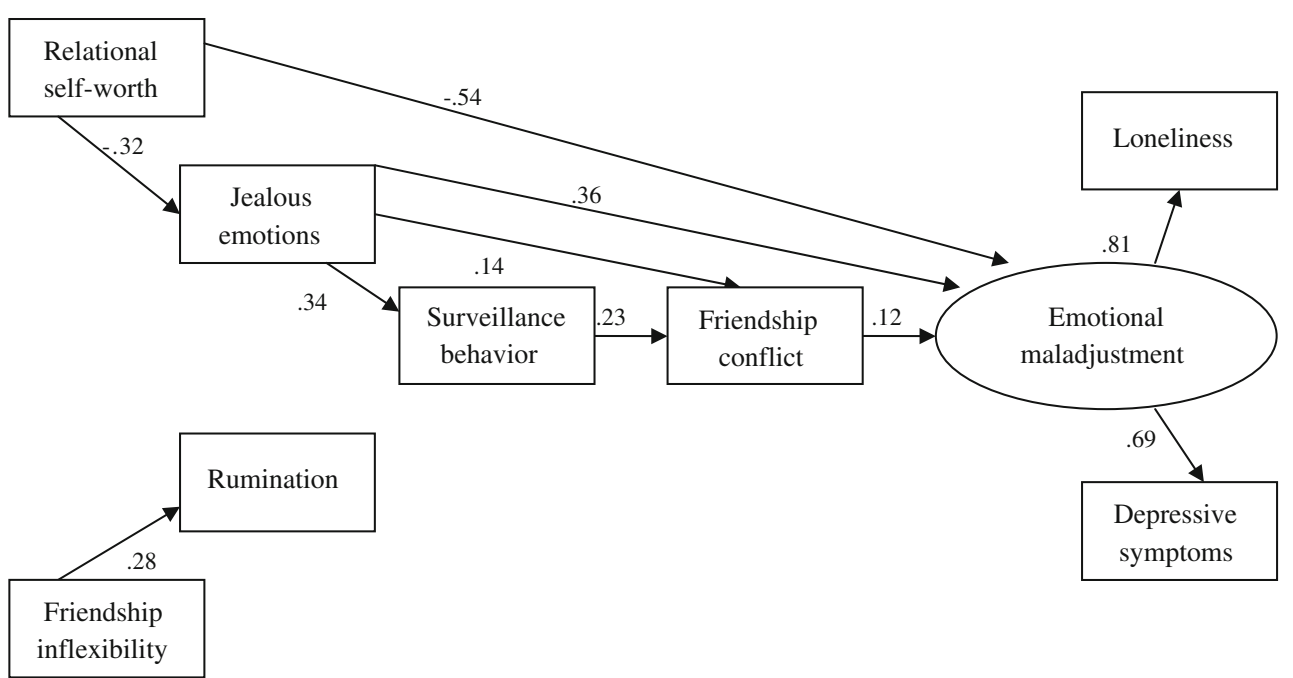

model. The goodness-of-fit index (GFI) indicated that the model accounted for $88 \%$ of the observed variances and covariances in the data. The model also appeared to provide a less-than-fully-adequate fit when accounting for the ratio of estimated parameters to observed variables (RMSEA= 0.091). Nonetheless, inspection of the individual pathways of even this strictly constrained model did reveal that, consistent with past findings, self-worth significantly predicted a vulnerability to jealousy (see Fig. 2). Moreover, as hypothesized, jealousy was linked to surveillance behavior and surveillance behavior in turn was linked to friendship conflict. Increased conflict between friends in turn, predicted greater emotional adjustment difficulties. Further, self-worth also directly contributed to emotional maladjustment in the expected direction.

Figure 3 depicts the standardized path and covariance estimates from the enhanced model, which took advantage of the information available on the early adolescents' inflexible thinking and proneness toward ruminating over friendship difficulties. Incorporating information on inflexibility and rumination into the model provided a significant improvement, $\Delta \chi^{2}(7)=119.53, p<0.001$, over the baseline model and produced an adequate fit overall, $\chi^{2}(47)=70.93, p<0.05$. The relative fit indices were $\mathrm{TLI}=0.95$ and $\mathrm{CFI}=0.96$. Further, the GFI indicated that the model accounted for $95 \%$ of the observed variances and covariances in the data and RMSEA was 0.041 . Examination of the critical ratios for differences between sexes indicated that the assumption of sex invariance was untenable in one specific instance, namely, the path from inflexibility to surveillance behavior (see Fig. 3). The fit of a less restrictive model in which this pathway was estimated separately for each sex was $\chi^{2}(46)=61.93, p=$ $0.05)$, a statistically significant improvement, $\Delta \chi^{2}(1)=$ 9.01, $p<0.01$. The relative fit of this final model was $\mathrm{TLI}=0.96$. The comparative fit was $\mathrm{CFI}=0.97$. RMSEA for the model was 0.034 and the GFI was 0.95 . The coefficients for boys and girls are given separately in Fig. 3 for this pathway.

As shown and as expected, lower self-worth was associated with greater inflexibility in attitudes toward friendship needs. Lower self-worth and inflexibility, in turn, predicted the tendency to experience feelings of jealousy. The tendency to be inflexible surrounding friendship was also associated with the tendency to ruminate over friendship difficulties and rumination was associated with further heightened feelings of jealousy. Self-worth was not directly related to rumination, although it was indirectly related through its association with inflexibility. As in the baseline model, feelings of jealousy were significantly linked with expressions of jealousy in the form of surveillance and other negative behaviors. In turn, surveillance behaviors and jealous feelings remained associated with broader conflict between friends. However, now surveillance behavior was further predicted by the tendency to ruminate over friendship problems and, for boys, by inflexible attitudes toward friendship. Whereas conflict between friends was related to broader emotional maladjustment in the baseline model, this link was not statistically significant in the more complete model incorporating information concerning rumination and inflexibility. Likewise, notwithstanding its indirect influences, rumination over friendship difficulties was not directly associated with emotional maladjustment. However, as expected, emotional maladjustment was directly and indirectly predicted by the set of variables that included selfworth, friendship inflexibility, and feelings of jealousy (see Fig. 3).

\section{Discussion}

All children regularly face the challenge of sharing the attention and affection of their friends with other peers. But 
Fig. 3 Final, comparative structural model predicting jealousy and adjustment with benefit of information on vulnerability to inflexible thinking and rumination. Note. All coefficients are standardized. All coefficients except those with a dashed line are statistically significant at $p<$ 0.05. ${ }^{\mathrm{g}}=$ girls $^{\mathrm{b}}=$ boys

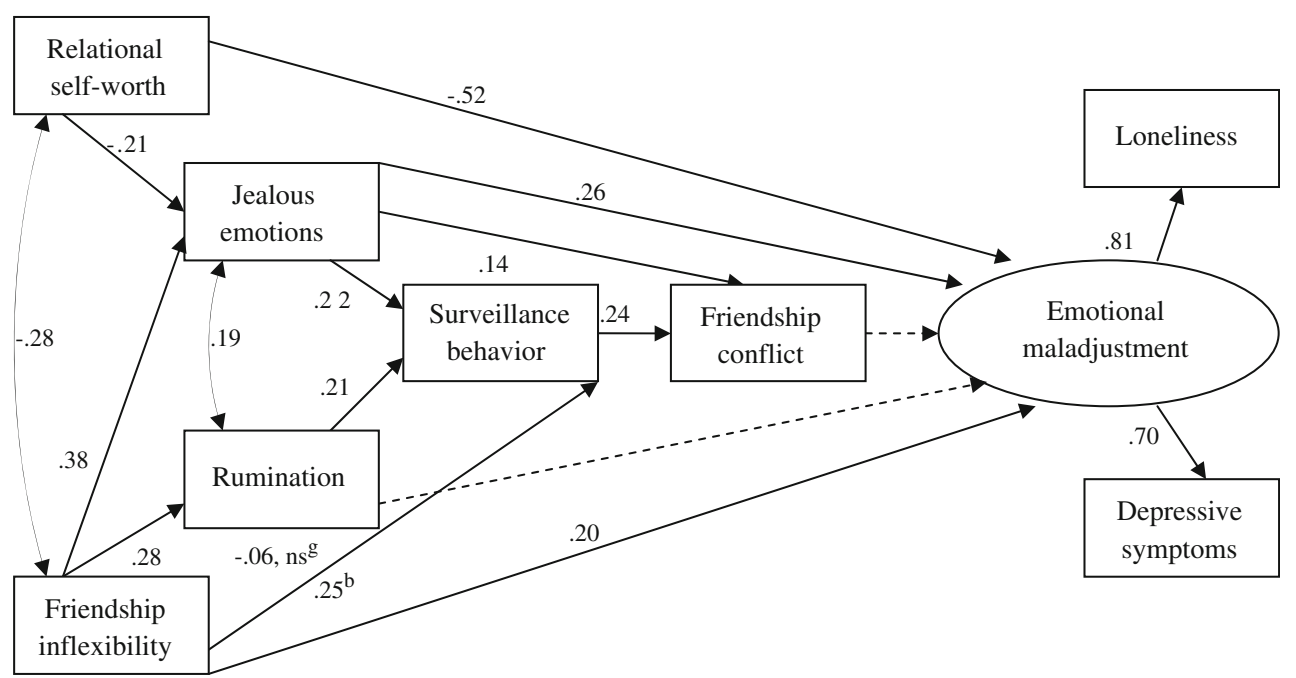

our results, like those from other recent studies, suggest that some children are especially vulnerable to feeling and expressing unwarranted or excessive jealousy around friends in these circumstances. The origin of this disposition is of significant interest as the present work, like past work (Parker et al. 2005), suggests that friendship jealousy is linked to problematic outcomes for children. For example, early adolescents in the present study who reported being vulnerable to friendship jealousy also reported engaging in surveillance and other negative behaviors towards friends, reported more conflict with friends, and expressed greater intrapersonal distress in the form of feelings of loneliness and depression.

Consistent with past research (Parker et al. 2005), the present data suggest that jealous dispositions may rest partly in individuals' negative views of themselves. Presumably individuals with feelings of low self-worth are especially vulnerable to jealousy because they are prone to draw negative social comparisons with interlopers and to exaggerate the risk that outsiders pose to their relationships. Conversely, individuals with higher self-regard presumably feel little competition with their friends' other friends and offer benign interpretations of their friends' activities with others. However, a significant implication of the present findings is that focusing solely on individuals' views of themselves provides an incomplete account of how jealousy arises. Instead, maladaptive views of relationships and other reasoning processes also enter into the perceptions of threat in jealousy or exacerbate the stress it represents. Specifically, even after considering self-worth, inflexible beliefs and a disposition to ruminate over friendship difficulties contributed value.

Flexibility is an inherent requirement of all social participation and has been implicated directly or indirectly in a number of conceptual models of cognition in close relationships (e.g., Crick and Dodge 1994; Lemerise and Arsenio 2000; Martin and Tesser 1996; Selman and Schultz
1990). In the present study, we posited that some individuals are unusually dogmatic in their beliefs towards friends, such that typical friendship roles and functions are narrowly and emphatically associated with a single, specific individual. When asked to imagine that this individual was temporarily or permanently unavailable, highly inflexible individuals have difficulty envisioning that they would be capable of reacting with resilience or generating alternatives. On the other hand, flexible individuals, while no less close to their friends, profess to be open to multiple possibilities for satisfying and fulfilling friendships, especially when asked to imagine that their initial or most desirous avenue was precluded. Individuals lacking this flexibility towards friends should experience greater jealousy around friends because such rigid attitudes presumably insure frequent frustration and magnify the threat posed by outsiders.

Our findings were largely consistent with these expectations. Relatively robust individual differences in friendship inflexibility were observed that were consistent across items in our newly created self-report measure, the resulting inflexibility scores were generally stable upon retesting, and these differences were relatively independent of the closeness of the relationships. More importantly, results from our structural modeling analyses were consistent with an interpretation that inflexible thinking concerning friends contributes directly to feelings of jealousy, and via this route to tendencies to engage in surveillance and other nuisance behaviors around friends. In addition, analyses were consistent with the interpretation that friendship inflexibility contributes to rumination surrounding problems with friends, which in turn was linked to jealous feelings. Ultimately, the experience and expression of jealousy appeared to contribute to friendship conflict and to intrapersonal distress.

It is important to stress that the links we observed with inflexibility were contemporary rather than predictive. 
Other models of the results might have been offered and future longitudinal and experimental work is necessary to have confidence in directional interpretations. A further difficulty is that we relied on self-reports to assess the disposition to jealousy along with all the other important assessments in this study. For most variables in our study (e.g., self-esteem, jealousy, intrapersonal distress, rumination, flexibility), self-reports are preferred assessments because these variables index subjective states and attitudes not available to outsiders. In other instances (e.g., friendship conflict), alternatives are available but were logistically impractical in the present case. Our reliance on self-reports should be treated with caution because our reliance on a common method may have enhanced the coherence of findings across constructs.

Assuming subsequent research yields results consistent with ours, further clarification of the nature and boundaries of the construct of friendship inflexibility appears warranted. For example, investigation of the generality of this disposition could be helpful. Are early adolescents who are inflexible toward friends also inflexible in other close personal relationship contexts (e.g., with siblings, parents, later romantic partners) and toward individuals who play important, but non-intimate roles in their lives (e.g., teachers)? Inflexibility toward associates of many types could indicate deeper, underlying cognitive deficits in how inflexible individuals represent the means connected to important social ends. Whether or not this disposition is part of a larger vulnerability, the present findings support authors who have called for greater attention to the requirements for successful friendship participation in the conceptualization and design of social skills interventions for this age (Asher et al. 1996). If adolescents can be successfully taught to think flexibly about their friends through training, our data suggest that some improvement in their disposition to jealousy and reduction of problems of conflict with friends might be observed.

Results also suggested that inflexible views of friendship contribute to rumination surrounding these relationships. Contemporary models of rumination in adults suggest that any cognitive or motivational process that prompts individuals to represent their goals or means to their goals in ways that are prone to frustration can also be expected leave those individuals vulnerable to rumination (McIntosh et al. 1995). Perhaps friendship disappointments, including a friend's unavailability due to other relationship commitments, bear more strongly on perceptions of their attainment of interpersonal goals when individuals view their friends in a rigid way. This circumstance is significant because early adolescents who reported ruminating over difficulties with friends in our study also reported greater feelings of jealousy and engaging more frequently in jealousy-related surveillance and nuisance behavior than early adolescents less preoccupied with their friendship problems. This was true even after considering the role of inflexible beliefs in these outcomes. Rumination also related to conflict within the friendship through its role in contributing to jealous feelings and behavior. Interestingly, Rose (2002) found that ruminating with a friend (coruminating) actually predicted greater friendship closeness in preadolescence. In contrast, the present data suggest that ruminating to oneself about friendship problems may lead to conflict in the relationship. These findings suggest the importance distinguishing between ruminating about friendship difficulties and ruminating with friends about difficulties. Individuals who perseverate on their difficulties with a friend may hasten the deterioration of that relationship, especially if they are unable to forgive their friend for some real or imagined transgression (Asher et al. 1996). However, when two friends co-ruminate about a difficulty they are having with a third peer, for example, they may grow closer to one another.

Surprisingly, rumination played little direct role in early adolescents' emotional maladjustment after jealousy, inflexibility, and self-worth were considered. As research with adults and young people in other contexts has repeatedly demonstrated links between rumination and intrapersonal distress, such as depression (i.e., Hart and Thompson 1996; Nolen-Hoeksema et al. 1993; Pyszczynski and Greenberg 1987; Rose 2002; Schwartz and Koenig 1996), the absence of a link in this study is noteworthy. In the past, ruminative cognitive style was typically defined generally, without regard to the specific subject of preoccupation. In the present study, however, we tapped early adolescents' tendencies to ruminate specifically around their problems with friends. While the tendency to ruminate around friendship difficulties is likely part of a broader disposition, it is possible that by employing a narrow definition of rumination, we weakened the ability of this construct to predict outcomes not specific to friendship (i.e., depression).

Finally, one secondary aim of the current study was to expand understanding of the behavior of jealous early adolescents beyond the vulnerability to general aggression that has been described in the past. We were particularly interested in jealousy-prone individuals' friendship experiences. Individuals who are prone to jealousy are highly motivated to save-face and protect their relationships. They need not behave problematically, but we proposed that when jealousy is coupled with inflexibility and proneness to distressing, repetitive, preoccupying thoughts concerning their friendship difficulties, a highly motivating state of uncertainty exists. One likely response to these circumstances is indirect information gathering, such as looking through friends' belongings or calling unexpectedly to monitor friends' other relationships (Carson and Cupach 2000; Guerrero et al. 1995; Pfeiffer and Wong 1989). 
Overall, girls reported more feelings of jealousy, more inflexibility, and greater loneliness and friendship rumination than did boys. As such, while both boys and girls presumably derive important positive benefits from their close friendships, to a greater degree than boys', girls' friendships also appear to also be associated with several significant negative emotions and vulnerabilities. This observation would seem consistent with the claims of some authors (e.g., Benenson and Christakos 2003) that, compared with boys', girls friendships are more fragile and less durable. Interestingly, while jealous feelings and rumination were related to surveillance for both boys and girls, a relation between flexibility and surveillance was present only for boys. Thus, while inflexibility was less characteristic of boys than girls, it was followed more predictably by surveillance behavior in boys. The basis of this difference is not clear. Perhaps this implies that girls who are inflexible are more resourceful in their response and display a wider range of resulting behavior, including some forms of adaptive responses, than do boys. However, compared with boys, girls were more likely to engage in surveillance of their friends in general, so perhaps this indicates that this behavior in girls serves many more purposes than it does in boys, and is thus less specific to the goal of reducing uncertainty concerning one's partner's commitment. These and other interpretations require further research clarification.

Surveillance of friends might be of some immediate benefit to jealous early adolescents but its broader impact is likely to be to exhaust their partner's goodwill and generate conflict. This is precisely the pattern we obtained. These findings are consistent with the literature on adults in romantic contexts, where jealousy has been recognized as a major contributor to relationship dissatisfaction (Anderson, et al. 1995; Bringle et al. 1979) and relationship conflict and violence (Hansen 1991; Stets and Pirog-Good 1987). Care must be exercised in interpreting these findings, as the individuals who provided the assessments of jealousy, rumination, and inflexibility were the same individuals who suggested that their relationship was full of conflict. Even so, these results encourage a closer look at the friendships of jealous-prone early adolescents in the future. It would be particularly helpful to learn if and how close friends become aware of their partners' insecurity and subterfuge, the attributions they make surrounding it, and circumstances under which they are willing to tolerate it. Further, to the extent that it might be important in the future to intervene and stabilize the friendship success of jealousyprone early adolescents, it would also be interesting to know whether jealous individuals grasp the irony implied by the possibility that their negative behavior is jeopardizing the very relationships they are so anxious to keep.

\section{References}

Anderson, P. A., Eloy, S. V., Guerrero, L. K., \& Spitzberg, B. H. (1995). Romantic jealousy and relational satisfaction: A look at the impact of jealousy experience and expression. Communication Reports, 8, 77-85.

Arbuckle, J. L., \& Wothke, W. (1999). Amos 4.0 user's guide. Chicago, IL: SmallWaters Corp.

Asher, S. R., \& Wheeler, V. A. (1985). Children's loneliness: A comparison of rejected and neglected peer status. Journal of Consulting and Clinical Psychology, 53, 500-505. doi:10.1037/ 0022-006X.53.4.500.

Asher, S. R., Parker, J. G., \& Walker, D. (1996). Distinguishing friendship from acceptance: Implications for intervention and assessment. In W. M. Bukowski, A. F. Newcomb \& W. W. Hartup (Eds.), The company they keep: Friendships in childhood and adolescence, pp. 366-405. Cambridge: Cambridge University Press.

Baldwin, M. W. (1992). Relational schemas and the processing of social information. Psychological Bulletin, 112, 461-484. doi:10.1037/0033-2909.112.3.461.

Benenson, J. F., \& Christakos, A. (2003). The greater fragility of females' versus males' closest same-sex friendships. Child Development, 74, 1123-1129. doi:10.1111/1467-8624.00596.

Bentler, P. M., \& Bonett, D. G. (1980). Significance tests and goodness of fit in the analysis of covariance structures. Psychological Bulletin, 88, 588-606. doi:10.1037/00332909.88.3.588.

Berger, C. R., \& Gudykunst, W. B. (1991). Uncertainty and communication. In B. Dervin \& M. Voight (Eds.), Progress in Communication Sciences, pp. 21-66. Norwood, NJ: Ablex.

Berger, C. R., \& Kellermann, K. (1994). Strategic interpersonal communication. In J. A. Daly \& J. M. Wiemann (Eds.), LEA's Communication Series, pp. 1-31. Hillsdale, NJ: Erlbaum.

Bradbury, T. N., \& Fincham, F. D. (1991). A contextual model for advancing the study of marital interaction. In G. J. O. Fletcher \& F. D. Fincham (Eds.), Cognition in close relationships, pp. 127147. Hillsdale, NJ, England: Erlbaum.

Bringle, R. G., Roach, S., Andier, C., \& Evenbeck, S. (1979). Measuring the intensity of jealous reactions. Catalog of Selected Documents in Psychology, 9 MS, 1832, 23-24.

Broderick, P. C. (1998). Early adolescent gender differences in the use of ruminative and distractive coping strategies. The Journal of Early Adolescence, 18, 173-191. doi:10.1177/0272431698018002003.

Buunk, B. P. (1997). Personality, birth order and attachment styles as related to various types of Jealousy. Personality and Individual Differences, 23, 997-1006. doi:10.1016/S0191-8869(97)00136-0.

Buunk, B. P., \& Bringle, R. G. (1987). Jealousy in love relationships. In D. Perlman \& S. Duck (Eds.), Intimate relationships: Development, dynamics, and deterioration, pp. 123-147. Thousand Oaks, CA: Sage Publications, Inc.

Carson, C. L., \& Cupach, W. R. (2000). Fueling the flames of the green-eyed monster: The role of ruminative thought in reaction to romantic jealousy. Western Journal of Communication, 64, 308-329.

Carver, C. S., Scheier, M. F., \& Weintraub, J. K. (1989). Assessing coping strategies: A theoretically based approach. Journal of Personality and Social Psychology, 56, 267-283. doi:10.1037/ 0022-3514.56.2.267.

Census (2000). As cited in http://en.wikipedia.org/wiki/Tyrone,_Penn sylvania, November 9, 2005.

Clanton, G. (1981). Frontiers of jealousy research. Alternative Lifestyles, 4, 259-273. doi:10.1007/BF01257940.

Crick, N. R., \& Dodge, K. A. (1994). A review and reformulation of social information-processing mechanisms in children's social 
adjustment. Psychological Bulletin, 115, 74-101. doi:10.1037/ 0033-2909.115.1.74.

Davis, R. N., \& Nolen-Hoeksema, S. (2000). Cognitive inflexibility among ruminators and non-ruminators. Cognitive Therapy and Research, 24, 699-711. doi:10.1023/A:1005591412406.

Erdley, C. A., \& Asher, S. R. (1999). A social goals perspective on children's social competence. Journal of Emotional and Behavioral Disorders, 7, 156-167. doi:10.1177/106342669900700304.

Fletcher, G. J., \& Fitness, J. (1990). Occurrent social cognition in close relationship interaction: The role of proximal and distal variables. Journal of Personality and Social Psychology, 59, 464-474. doi:10.1037/0022-3514.59.3.464.

Guerrero, L. K., \& Afifi, W. A. (1999). Toward a goal-oriented approach for understanding communicative responses to jealousy. Western Journal of Communication, 63, 216-248.

Guerrero, L. K., \& Anderson, P. A. (1998). The dark side of jealousy and envy: Desire, delusion, desperation, and destructive communication. In B. H. Spitzberg \& W. R. Cupach (Eds.), The dark side of close relationships, pp. 33-70. Mahwah, NJ: Erlbaum.

Guerrero, L. K., Anderson, P. A., Jorgensen, P. F., Spitzberg, B. H., \& Eloy, S. V. (1995). Coping with the green-eyed monster: Conceptualizing and measuring communicative responses to romantic jealousy. Western Journal of Communication, 59, 270-304.

Hansen, G. L. (1991). Jealousy: Its conceptualization, measurement, and integration within family stress theory. In P. Salovey (Ed.), The psychology of jealousy and envy, pp. 252-272. New York: Guilford.

Hart, B. I., \& Thompson, J. M. (1996). Gender role characteristics and depressive symptomatology among adolescents. The Journal of Early Adolescence, 16, 407-426. doi:10.1177/0272431696016004003.

Harter, S. (1988). The Self-Perception Profile for Adolescents. University of Denver: Unpublished manual.

Harter, S., Waters, P., \& Whitesell, N. R. (1998). Relational selfworth: Differences in perceived worth as a person across interpersonal contexts among adolescents. Child Development, 69, 756-766.

Hu, I. T., \& Bentler, P. M. (1995). Evaluating model fit. In R. H. Hoyle (Ed.), Structural equation modeling, pp. 45-73. Thousand Oaks, CA: Sage Publications.

Kovacs, M. (1992). Children's Depression Inventory. New York: Multi-Health Systems.

Lemerise, E. A., \& Arsenio, W. F. (2000). An integrated model of emotion processes and cognition in social information processing. Child Development, 71, 107-118. doi:10.1111/1467-8624.00124.

Martin, L. L., \& Tesser, A. (1996). Some ruminative thoughts. In R. S. Wyer (Ed.), Ruminative thoughts (Advances in social cognition, Vol. IX), pp. 1-47. Mahwah, NJ: Erlbaum.

Mathes, E. W. (1991). Dealing with romantic jealousy by finding a replacement relationship. Psychological Reports, 69, 535-538. doi:10.2466/PR0.69.6.535-538.

McIntosh, W. D., \& Martin, L. L. (1992). The cybernetics of happiness: The relation between goal attainment, rumination, and affect. In M. S. Clark (Ed.), Review of personality and social psychology, Vol. 14, pp. 222-246. Newbury Park, CA: Sage.

McIntosh, W. D., Harlow, T. F., \& Martin, L. L. (1995). Linkers and non-linkers: Goal beliefs as a moderator of the effects of everyday hassles on rumination, depression and physical complaints. Journal of Applied Social Psychology, 25, 1231-1244. doi:10.1111/j.1559-1816.1995.tb02616.x.

McIntosh, W. D., Martin, L. L., \& Jones, J. B. (1997). Goal beliefs, life events, and the malleability of people's judgments of their happiness. Journal of Social Behavior and Personality, 12, 567-575.
Miller, J. B. (1996). Social flexibility and anxious attachment. Personal Relationships, 3, 241-256. doi:10.1111/j.14756811.1996.tb00115.x.

Nolen-Hoeksema, S. (2000). The role of rumination in depressive disorders and mixed a anxiety/depressive symptoms. Journal of Abnormal Psychology, 109, 504-511. doi:10.1037/0021843X.109.3.504.

Nolen-Hoeksema, S., \& Morrow, J. (1991). A prospective study of depression and posttraumatic stress symptoms after a natural disaster: The 1989 Loma Prieta earthquake. Journal of Personality and Social Psychology, 61, 115-121. doi:10.1037/00223514.61.1.115.

Nolen-Hoeksema, S., Morrow, J., \& Fredrickson, B. L. (1993). Response styles and the duration of episodes of depressed mood. Journal of Abnormal Psychology, 102, 20-28. doi:10.1037/0021843X.102.1.20.

Nolen-Hoeksema, S., Larson, J., \& Grayson, C. (1999). Explaining the gender difference in depressive symptoms. Journal of Personality and Social Psychology, 77, 1061-1072. doi:10.1037/0022-3514.77.5.1061.

Parker, J. G., \& Asher, S. R. (1993). Friendship and friendship quality in middle childhood: Links with peer group acceptance and feelings of loneliness and social dissatisfaction. Developmental Psychology, 29, 611-621. doi:10.1037/00121649.29.4.611.

Parker, J. G., \& Gamm, B. K. (2003). Describing the dark side of children's peer experiences: Four questions (and data) on children's enemies. In E. V. E. Hodges \& N. Card (Eds.), Enemies and the darker side of peer relations: New directions for child and adolescent development, 102, pp. 55-72. San Francisco: Jossey-Bass.

Parker, J. G., \& Ramich, C. W. (2003). Third party peers as interlopers: Role of outside peer interference in preadolescents feelings and thoughts surrounding friendship disappointments. Unpublished manuscript.

Parker, J. G., Low, C., Walker, A. W., \& Gamm, B. K. (2005). Children's friendship jealousy: Assessment of individual differences and links to gender, self-esteem, aggression, and social adjustment. Developmental Psychology, 41, 235-250. doi:10.1037/0012-1649.41.1.235.

Parrott, G. W., \& Smith, R. H. (1993). Distinguishing the experiences of envy and jealousy. Journal of Personality and Social Psychology, 64, 906-920. doi:10.1037/0022-3514.64.6.906.

Pfeiffer, S. M., \& Wong, P. T. P. (1989). Multidimensional jealousy. Journal of Social and Personal Relationships, 6, 181-196. doi:10.1177/026540758900600203.

Planlap, S., \& Honeycutt, J. M. (1985). Events that increase uncertainty in personal relationships. Human Communication Research, 11, 593-604. doi:10.1111/j.1468-2958.1985.tb00062.x.

Pyszczynski, T., \& Greenberg, J. (1987). Self-regulatory perseveration and the depressive self-focusing style: A self-awareness theory of reactive depression. Psychological Bulletin, 102, 122-138. doi:10.1037/0033-2909.102.1.122.

Rawlins, W. K. (1992). Friendship matters: Communication, dialectics, and the life course. New York: Aldine de Gruyter.

Rose, A. J. (2002). Co-rumination in the friendships of girls and boys. Child Development, 73, 1830-1843. doi:10.1111/14678624.00509.

Roth, M. A., \& Parker, J. G. (2001). Affective and behavioral responses to friends who neglect their friends for dating partners: Influences of gender, jealousy and perspective. Journal of Adolescence, 24, 281-296. doi:10.1006/ jado.2001.0408.

Salovey, P., \& Rodin, J. (1989). Envy and jealousy in close relationships. Review of Personality and Social Psychology, 10, 221-246. 
Schwartz, J. A. J., \& Koenig, L. J. (1996). Response styles and negative affect among adolescents. Cognitive Therapy and Research, 20, 13-36. doi:10.1007/BF02229241.

Selman, R. L. (1980). The growth of interpersonal understanding: Developmental and clinical analyses. New York: Academic Press.

Selman, R. L., \& Schultz, L. H. (1990). Making a friend in youth: Developmental theory and pair therapy. Chicago, IL: University of Chicago Press.
Sharpsteen, D. J. (1991). The organization of jealousy knowledge: Romantic Jealousy as a blended emotion. In P. Salovey (Ed.), The psychology of jealousy and envy, pp. 31-51. New York: Guilford Press.

Stets, J. E., \& Pirog-Good, M. A. (1987). Violence in dating relationships. Social Psychology Quarterly, 50, 237-246. doi: $10.2307 / 2786824$.

White, G. L. (1981). A model of romantic jealousy. Motivation and Emotion, 5, 295-310. doi:10.1007/BF00992549. 